Article

\title{
Attenuation of Spatial Memory in 5xFAD Mice by Halting Cholinesterases, Oxidative Stress and Neuroinflammation Using a Cyclopentanone Derivative
}

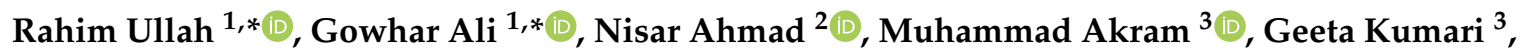 \\ Muhammad Usman Amin ${ }^{4}$ and Muhammad Naveed Umar ${ }^{5}$ \\ 1 Department of Pharmacy, University of Peshawar, Peshawar 25120, Pakistan \\ 2 Department of Pharmacy, National University of Pakistan, Pasrur Road, Sialkot 51310, Punjab, Pakistan; \\ nisarahmadsatal@yahoo.com \\ 3 Department of Pharmacology, Faculty of Pharmacy, University of Sindh, Jamshoro 76080, Pakistan; \\ akramkhatrisu@yahoo.com (M.A.); geeta.kumari@usindh.edu.pk (G.K.) \\ 4 Department of Pharmacy, Abasyn University, Ring Road, Peshawar 25120, Pakistan; \\ usman.amin@abasyn.edu.pk \\ 5 Department of Chemistry, University of Malakand, Chakdara 18000, Dir (L), KPK, Pakistan; \\ m.naveedumar@uom.edu.pk \\ * Correspondence: Rphrahimullah@gmail.com (R.U.); gowhar_ali@uop.edu.pk (G.A.); \\ Tel.: +92-3469430641 (R.U.); +92-3339317832 (G.A.); Fax: +92-91921813 (G.A.)
}

Received: 10 September 2020; Accepted: 10 October 2020; Published: 19 October 2020 updates

\begin{abstract}
Alzheimer's disease (AD) is an irreversible and chronic neurological disorder that gradually destroys memory and thinking skills. The research study was designed to investigate the underlying molecular signaling involved in the neuroprotective effects of cyclopentanone derivative i.e., 2-(hydroxyl-(3-nitrophenyl)methyl)cyclopentanone (3NCP) as a therapeutic agent for AD. In this study, In vivo studies were carried out on a well-known 5xFAD mice model using different behavioural test models such as open field, rotarod, Morris water maze (MWM), and Y-maze tests. Furthermore, in vitro cholinesterase inhibition activity assays were carried out. The frontal cortex (FC) and hippocampus (HC) homogenates were tested for the levels/activities of cholinesterases, glutathione (GSH), glutathione S-transferase (GST), and catalase. Furthermore, the hippocampal expression of inflammatory cytokines was observed via RT-PCR and western blot. The results of in vivo studies show an enhancement in the learning behavior. The $3 \mathrm{NCP}$ treatment reduced latency time in MWM and Y-maze tests, also increase spontaneous alternation indicate significant effect of $3 \mathrm{NCP}$ on memory. Furthermore, open field and rotarod studies revealed that $3 \mathrm{NCP}$ does not cause motor coordination deficit. The results of the in vitro studies revealed that the $\mathrm{IC}_{50}$ values of the $3 \mathrm{NCP}$ against acetylcholinesterase $(A C h E)$ and butyrylcholinesterase $(B C h E)$ were 16.17 and $20.51 \mu \mathrm{g} / \mathrm{mL}$, respectively. This decline in $A C h E$ and $B C h E$ was further supported by ex vivo studies. Further, the $3 \mathrm{NCP}$ mitigates the GSH level, GST, and catalase activities in HC and FC. The mRNA and protein expression of inflammatory cytokines (IL-1 $\beta$, IL-6, TNF- $\alpha$ ) markedly declined in RT-PCR and western blotting. The results of the current study conclusively demonstrate that $3 \mathrm{NCP}$ reduces oxidative stress and mitigates neuroinflammation in $5 \mathrm{xFAD}$ mice, implying that $3 \mathrm{NCP}$ may be a potential therapeutic candidate for $\mathrm{AD}$ treatment in the future.
\end{abstract}

Keywords: Alzheimer disease; cholinesterases; oxidative stress; neuroinflammation; spatial memory; 5xFAD mouse model 


\section{Introduction}

Alzheimer's disease (AD) is a progressive and chronic neurodegenerative disorder of the brain that gradually destroys the memory of patients and their capability of making decisions, learning, communication, and performing routine activities. Initially, in AD, short term memory gets disturbed, due to degeneration and dysfunction of neurons in the amygdala and hippocampus, progressing further to neuronal death in other cortical regions of the brain [1]. These brain regions are greatly involved in learning and memory processes. AD has been considered a major cause of dementia that represents a major socioeconomic burden for aging-societies. Hence, researchers are investigating AD pathology to develop effective therapeutic strategies. Many potential pathophysiologic mechanisms for the development of $\mathrm{AD}$ have been proposed, like neuroinflammation, oxidative stress, and microglial dysfunctions, among others [2,3]. This disorder is majorly linked with a cholinergic-deficit in the brain. Acetylcholinesterase $(A C h E)$ and butyrylcholinesterase $(B C h E)$ inhibit $A C h$, which plays a vital role in the AD pathogenesis. Currently, only two classes of drugs, acetylcholinesterase inhibitors (AChEIs) and $N$-methyl-D-aspartate (NMDA) receptor antagonists are approved, that are involved in the symptomatic treatment of $\mathrm{AD}$. Synthetic drugs, however, are useful for the management of such diseases, however they carry severe side effects [4]. The presence of untoward effects not only limits their use in clinical setups, but also drives the modern day researcher in the search for novel targeted drug molecules with higher efficacy and lesser side effects [5]. Reactive oxygen species (ROS) produced in the human body due to complex redox reactions contribute to cellular aging and neuronal damage. The destructive effects of these ROS are diminished by certain proteins and enzymes in human body such as GSH, GST, and catalase. A decline in levels/activities of these protein and enzymes from that of the free radicals leads to oxidative stress and finally certain chronic diseases, including AD. Hence, the use of antioxidants reduces $\mathrm{AD}$ progression and diminishes neuronal degeneration [6].

Inflammation is another hallmark of $\mathrm{AD}$. In $\mathrm{AD}$ brains, $\mathrm{A} \beta$ plaques are surrounded by activated microglial cells and reactive astrocytes. In addition, several inflammatory mediators including interleukin-1 $\beta$ (IL-1 $\beta$ ), interleukin-6 (IL-6) and tumor necrosis factor- $\alpha$ (TNF- $\alpha$ ) have been found within plaques [7]. Unfortunately, an effective treatment for $\mathrm{AD}$ is still lacking, therefore, the search for more effective anti-AD synthetic compounds with anticholinesterase, antioxidant, and anti-inflammatory properties, is desired.

Cyclopentanone derivatives have been reported to exhibit anti-inflammatory, analgesic, antioxidant, anticoagulant, anti- $A C h E$, and anti-BChE activities [8-11]. Following up on this perspective the cyclopentanone derivative 2-(hydroxy-(3-nitrophenyl)methyl)cyclopentanone (3NCP, Figure 1) [12] was evaluated as a possible potential candidate against $\mathrm{AD}$. The inhibition of $A C h E$ and $B C h E$, also the antioxidant activities has been attributed to the presence of the nitrophenyl group [13-17]. The ketone moiety exhibited dose-dependent antioxidant effects, which have been considered as a possible explanation for the decline of chronic neurodegenerative disorders like AD [18].

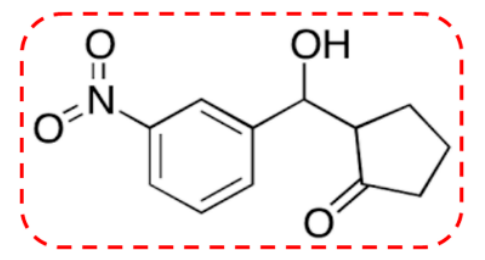

Figure 1. Chemical structure of 2-(hydroxy-(3-nitrophenyl)methyl)cyclopentanone. 


\section{Results}

\subsection{Behavioral Studies}

\subsubsection{Open Field Test}

This test is used to measure the locomotor activity, anxiety, and exploratory behavior in mice. Rearing, grooming behavior, and time spent in center were observed. 5xFAD mice displayed reduced number of rearing, more grooming and similar locomotor activity as compared to WT mice. While 3NCP $(40 \mathrm{mg} / \mathrm{kg})$ treated 5xFAD mice displayed a significant increase in the number of rearing $(p<0.001)$ and decrease in the number of grooming $(p<0.05)$, while, 3NCP did not change locomotor activity (Figure 2).
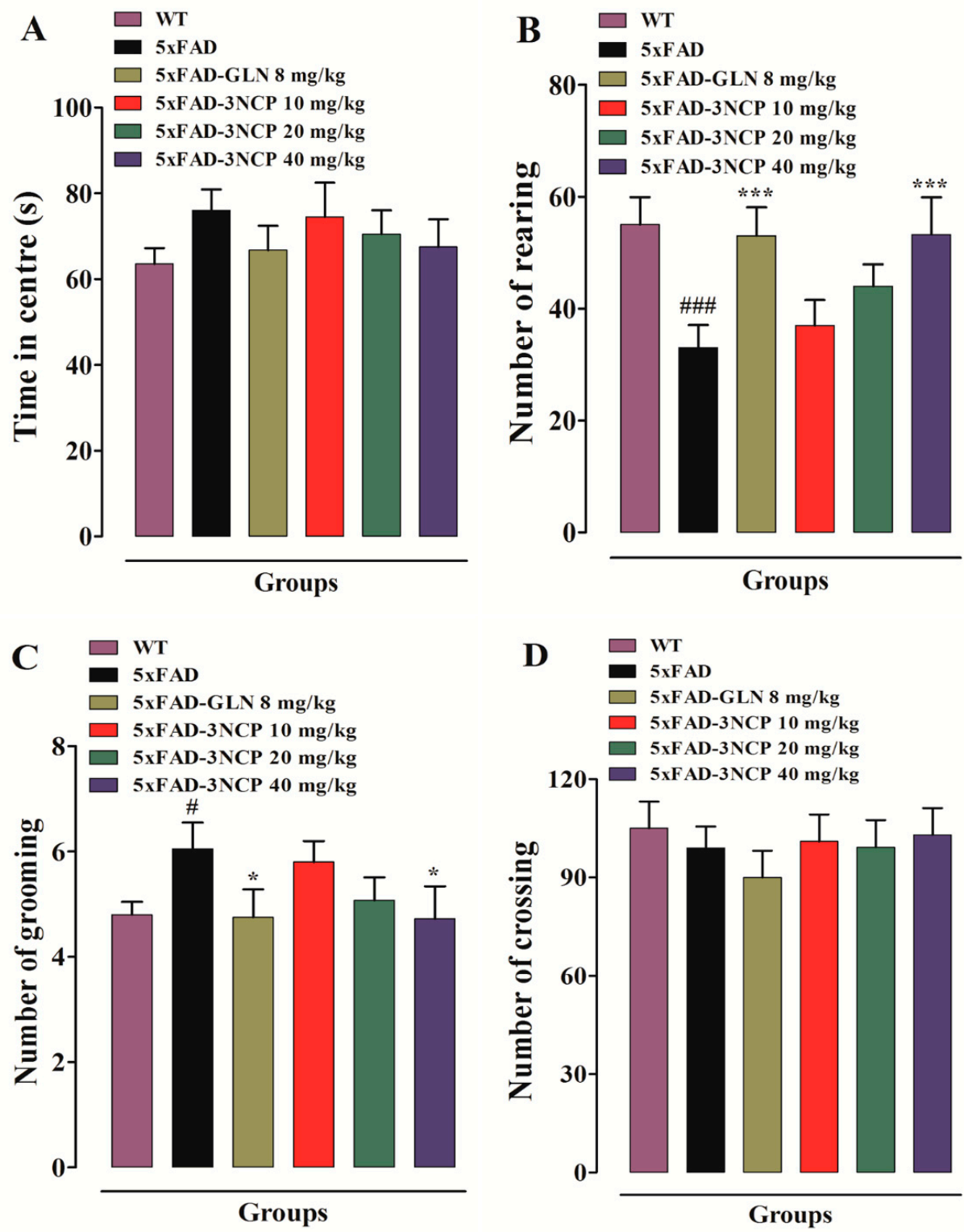

Figure 2. (A) Time in center; (B) number of rearing events; (C) number of grooming and (D) number of square crossing in the open field test after treatment with $3 \mathrm{NCP} /$ vehicle/galanthamine. Bars represent mean \pm SEM. ${ }^{*} p<0.05,{ }^{* * *} p<0.001$ compared to 5xFAD mice, ${ }^{\#} p<0.05$ and ${ }^{\# \#} p<0.001$ compared to non-transgenic WT-mice. Data was analyzed with one-way ANOVA followed by Dunnett post hoc test ( $n=10$ mice/group). 


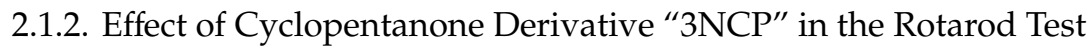

In the rotarod test the 5xFAD mice and non-transgenic mice fell from the rod in same time and did not display any defects in their motor-coordination and balance. A similar latency time was observed in case of 3NCP- and galanthamine-treated 5xFAD mice (Figure 3).

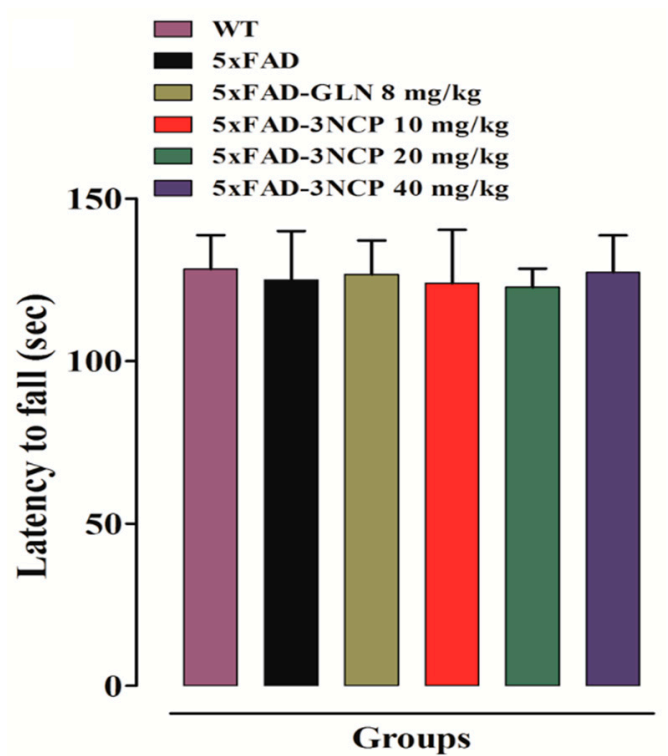

Figure 3. The effect of $3 \mathrm{NCP}$ on balance and motor coordination in the rotarod test. Bars represent mean \pm SEM. Data was analyzed with one-way ANOVA followed by Dunnett post hoc test ( $n=10$ mice/group).

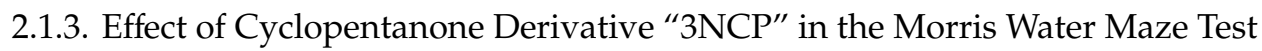

In the MWM test, escape latency time was observed for each group. The results showed that the $5 x F A D$ animals exhibited an increase in latency time as compared to WT-animals $(p<0.001)$. The $3 \mathrm{NCP}$ at the dose of $10 \mathrm{mg} / \mathrm{kg}(p<0.05)$ and at $20 \mathrm{mg} / \mathrm{kg}(p<0.01, p<0.001)$ reduced latency time significantly on day 4 and 5 , while at high dose of $40 \mathrm{mg} / \mathrm{kg}$ and galanthamine $(8 \mathrm{mg} / \mathrm{kg})$ caused a significant decline in latency-time on day 3 to 5 , time $=(F(4,90)=49.9, p<0.0001)$, treatment $=(F(5,90)=40.6$, $p<0.0001)$, interaction $=(\mathrm{F}(20,90)=1.53, p<0.09090)]$. In the probe test, 5xFAD mice spent less time in the target quadrant and less number of target quadrant crossings, while $3 \mathrm{NCP}$-treated mice demonstrated a reciprocal behaviour to this $(p<0.05, p<0.01, p<0.001)$ (Figure 4 ).
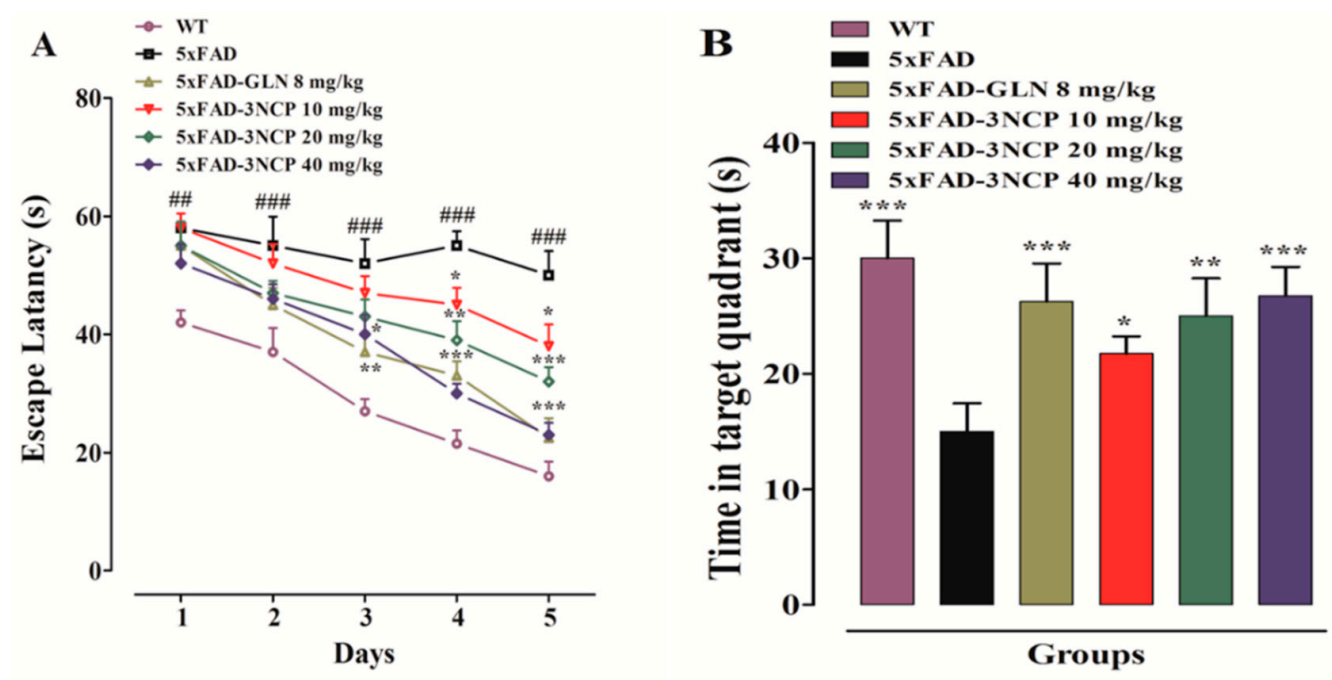

Figure 4. Cont. 

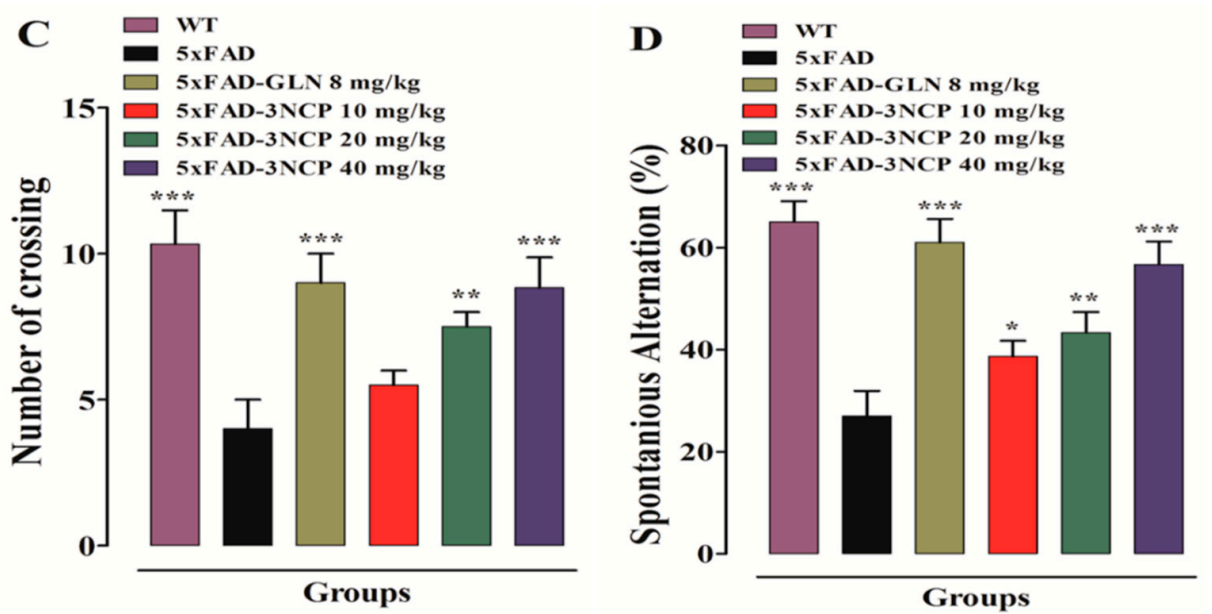

Figure 4. The effect of $3 \mathrm{NCP}$ on escape latency in MWM (A), time in target quadrant in probe test of MWM task (B), number of target crossing in probe test (C), and the effect of 3NCP on SAB in the Y-maze test (D). Bars express mean \pm SEM. ${ }^{*} p<0.05,{ }^{* *} p<0.01,{ }^{* * *} p<0.001$ compared to 5xFAD group, ${ }^{\# \#} p<0.001$ and ${ }^{\# \#} p<0.001$ compared to non-transgenic WT group. Data was analyzed by two-way ANOVA followed by Bonferroni test, and one-way ANOVA followed by Tukey's post-hoc test ( $n=10 \mathrm{mice} /$ group).

\subsubsection{Effect of Cyclopentanone Derivative "3NCP"in the Y-Maze Test}

Spontaneous alternation testing derived from SAB is a behavioral assessment method. It is used to investigate exploratory behavior and cognitive function related to spatial learning and working memory. The alternation behavior of mice was determined from successive entries into three arms on overlapping triplet sets in which three different arms are entered. 5xFAD mice treated with vehicle displayed a decreased in $\% \mathrm{SAB}$, while treatment with $3 \mathrm{NCP}$ and galanthamine significantly increased the $\% \mathrm{SAB}$ as compared to WT mice $(p<0.05, p<0.01, p<0.001)$, indicating that $3 \mathrm{NCP}$ ameliorated memory dysfunction in 5xFAD mice (Figure 4).

\subsection{In Vitro Cholinesterases Inhibition by Cyclopentanone Derivative " $3 N C P$ "}

The in vitro assay results of $3 \mathrm{NCP}$ against cholinesterases $(A C h E, B C h E)$ are shown in Table 1.

Table 1. Results of in vitro cholinesterases inhibitory assay of 2-(hydroxy-(3-nitrophenyl) methyl)cyclopentanone.

\begin{tabular}{|c|c|c|c|c|c|}
\hline \multirow[t]{2}{*}{ Samples } & \multirow[t]{2}{*}{ Conc. $(\mu \mathrm{g} / \mathrm{mL})$} & \multicolumn{2}{|c|}{ Acetylcholinesterase (AChE) } & \multicolumn{2}{|c|}{ Buterylcholinesterase $(B C h E)$} \\
\hline & & Inhibition (\%) & $\mathrm{IC}_{50} \mu \mathrm{g} / \mathrm{mL}$ & Inhibition (\%) & $\mathrm{IC}_{50} \mu \mathrm{g} / \mathrm{mL}$ \\
\hline \multirow{9}{*}{$3 \mathrm{NCP}$} & 07.8 & $16.17 \pm 1.53$ & \multirow{2}{*}{16.17} & $66.0 \pm 2.65$ & \multirow{2}{*}{20.51} \\
\hline & 15.6 & $25.0 \pm 5.0^{*}$ & & $224.0 \pm 5.29$ & \\
\hline & 31.25 & $45.7 \pm 4.04$ & & $44.3 \pm 6.03$ & \multirow{14}{*}{14.43} \\
\hline & 62.5 & $57.0 \pm 3.0$ & \multirow{13}{*}{13.12} & $55.0 \pm 4.36 *$ & \\
\hline & 125 & $65.3 \pm 4.16$ & & $65.8 \pm 1.89$ & \\
\hline & 250 & $72.3 \pm 3.06$ & & $71.0 \pm 5.57$ & \\
\hline & 500 & $77.0 \pm 3.0$ & & $76.0 \pm 1.73$ & \\
\hline & 1000 & $84.9 \pm 5.0$ & & $86.3 \pm 5.51$ & \\
\hline & 07.8 & $11.3 \pm 1.6$ & & $16.0 \pm 2.0$ & \\
\hline \multirow{7}{*}{ Galantamine } & 15.6 & $36.0 \pm 2.0$ & & $31.7 \pm 5.77$ & \\
\hline & 31.25 & $54.0 \pm 3.0$ & & $57.0 \pm 2.0$ & \\
\hline & 62.5 & $62.0 \pm 2.0$ & & $70.0 \pm 5.0$ & \\
\hline & 125 & $71.0 \pm 2.2$ & & $75.0 \pm 5.0$ & \\
\hline & 250 & $77.0 \pm 3.0$ & & $80.0 \pm 4.5$ & \\
\hline & 500 & $84.7 \pm 2.0$ & & $88.0 \pm 4.0$ & \\
\hline & 1000 & $88.7 \pm 4.15$ & & $91.3 \pm 2.31$ & \\
\hline
\end{tabular}

It has concentration-dependent inhibitory properties against these enzymes. Inhibition was observed as $16.17 \%$ and $6 \%$ at $7.8 \mu \mathrm{g} / \mathrm{mL}$, while it was $84.9 \%$ and $86.3 \%$ at $1000 \mu \mathrm{g} / \mathrm{mL}$. The $\mathrm{IC}_{50}$ values of 16.17 and $20.51 \mu \mathrm{g} / \mathrm{mL}$ against $A C h E$ and $B C h E$ were determined. Similarly, galanthamine caused inhibition of $A C h E$ and $B C h E$, which was 11.3 and $16 \%$ at $7.8 \mu \mathrm{g} / \mathrm{mL}$, whereas it was $88.7 \%$ and $91.3 \%$ at $1000 \mu \mathrm{g} / \mathrm{mL}$, with $\mathrm{IC}_{50}$ values of 13.12 and $14.43 \mu \mathrm{g} / \mathrm{mL}$. * $p<0.005$ compared to galanthamine treatment. 


\subsection{Ex Vivo Cholinesterases}

\subsubsection{Effect of Cyclopentanone Derivative $3 \mathrm{NCP}$ on Cortical and Hippocampal AChE, BChE Activities}

A significant decline in the percent $A C h E$ activities in the hippocampus (HC) was observed after treatment with $3 \mathrm{NCP}$ and galanthamine $(\mathrm{F}(5,12)=25, p<0.0001)$ and in frontal-cortex $(\mathrm{FC})$ $(\mathrm{F}(5,12)=34.2, p<0.0001)$ (Figure 5A). Similarly, 3NCP and galanthamine induced a decline in the percent $B C h E$ activities in $\mathrm{HC}(\mathrm{F}(5,12)=23.2, p<0.0001)$ and in $\mathrm{FC}(\mathrm{F}(5,12)=35.1, p<0.0001)$ (Figure 5B). 5xFAD mice exhibited a significant enhancement in $A C h E$ and $B C h E$ activities in $\mathrm{HC}$ and FC $(p<0.001)$, while, 5xFAD mice treated with galanthamine and 3NCP $(10,20$ and $40 \mathrm{mg} / \mathrm{kg})$ displayed a significant decline in $A C h E$ and BChE activities $(p<0.05, p<0.01, p<0.001)$.
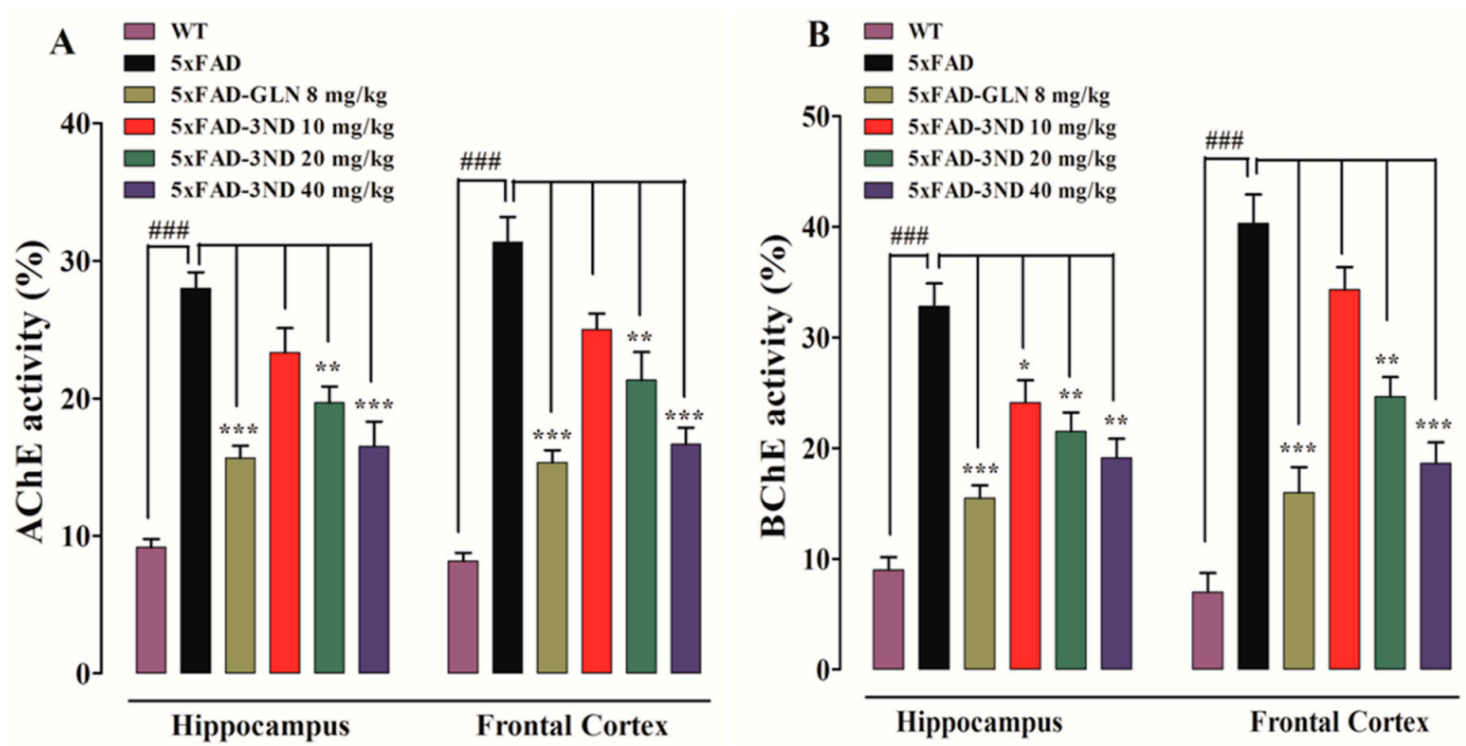

Figure 5. The effect of $3 \mathrm{NCP}$ on $A C h E$ level in $\mathrm{HC}$ and FC (A), the effect of $3 \mathrm{NCP}$ on the $B C h E$ level in both regions of brain (B). Data represent mean \pm SEM. ${ }^{*} p<0.05,{ }^{* *} p<0.01,{ }^{* * *} p<0.001$ compared to $5 \mathrm{xFAD}$ mice, ${ }^{\# \#} p<0.001$ compared to non-transgenic WT-mice, one-way ANOVA followed by Tukey's post hoc test $(n=4)$.

\subsubsection{Effect of Cyclopentanone Derivative 3NCP on GSH Level, GST, and Catalase Activities}

The GSH level, GST and catalase activities declined in the HC and FC of 5xFAD transgenic mice as compared to non-transgenic WT mice. The 3NCP-treated 5xFAD mice displayed an increased level of GSH in HC $(F(5,12)=52, p<0.0001$ and in FC $(F(5,12)=28.4, p<0.0001$. The 3NCP at doses of 20 and $40 \mathrm{mg} / \mathrm{kg}$ enhanced the percent GSH level significantly in HC and FC $(p<0.05, p<0.01$, $p<0.001)$. The GST activity increased in 3NCP-treated 5xFAD mice in $\mathrm{HC}(\mathrm{F}(5,12)=22.4, p<0.0001)$ and in FC $(F(5,12)=20, p<0.000)$, at doses of 10,20 , and $40 \mathrm{mg} / \mathrm{kg}$. Likewise, the 3NCP-treated transgenic mice displayed an increase in catalase activity $(\%)$ in $\operatorname{HC}(\mathrm{F}(5,12)=18.2, p<0.0001)$ and in $\mathrm{FC}(\mathrm{F}(5,12)=14.7, p<0.000)$ at doses of 10,20 , and $40 \mathrm{mg} / \mathrm{kg}$ (Figure 6). 

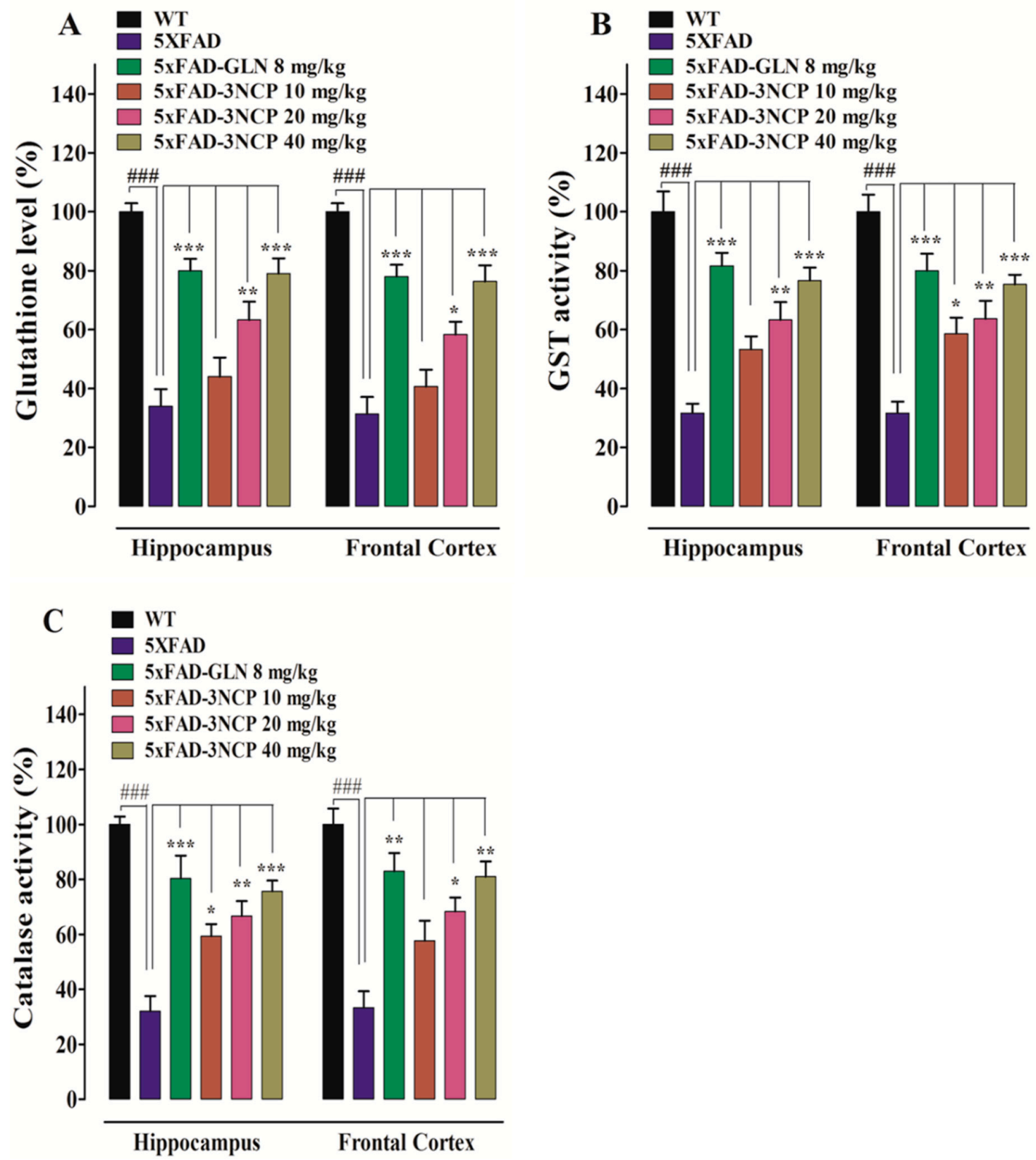

Figure 6. The effect of the 3NCP on \%-level of GSH (A), \%-activity of GST (B), and catalase (C), in the FC and HC. Bars displays mean level/activities (\%) \pm SEM. $^{*} p<0.05,{ }^{* *} p<0.01,{ }^{* * *} p<0.001$ compared to 5xFAD group and ${ }^{\# \#} p<0.001$ compared to non-transgenic WT-group, one-way ANOVA followed by Tukey's post hoc test $(n=4)$.

2.3.3. Effect of Cyclopentanone Derivative 3NCP on Cytokines (IL-1 $\beta$, IL-6, TNF- $\alpha$ ) in HC and FC Tissues

To assess the anti-inflammatory activities of 3NCP, the expression of different cytokines was evaluated in the hippocampal and frontal cortex tissues through RT-PCR. The 5xFAD mice treated with $3 \mathrm{NCP}$ and galanthamine revealed a significant decline in the mRNA levels of different cytokines (IL-1 $\beta$, IL-6, TNF- $\alpha$ ) as compared to the $5 x$ FAD mice $(p<0.01, p<0.001)$ (Figure 7). 

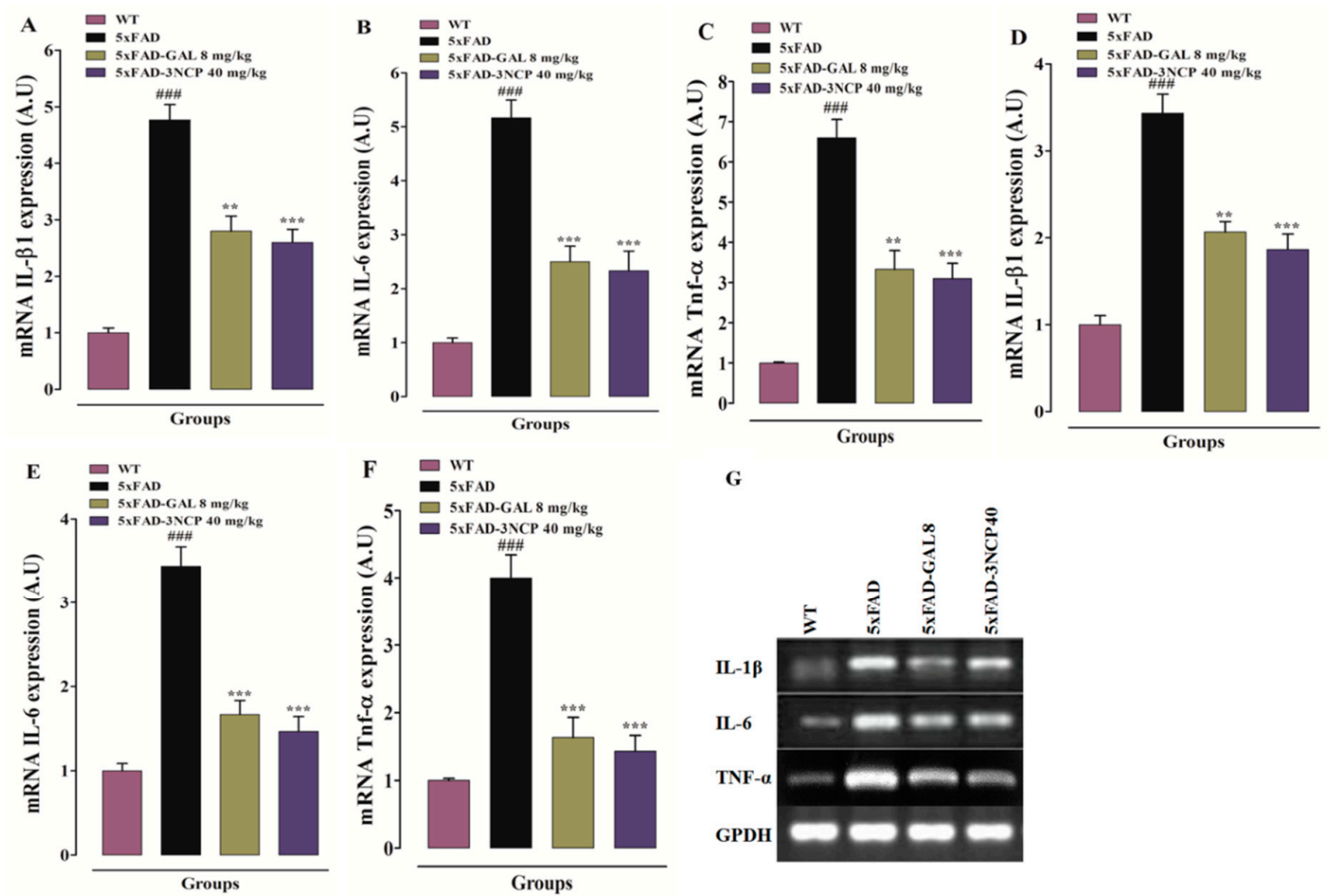

Figure 7. Animals were treated with $3 \mathrm{NCP}$ for 28 days and the mRNA expression of IL- $1 \beta$, IL-6, and TNF- $\alpha$ in hippocampus (A-C) and frontal cortex (D-F) was measured. The effect of $3 N C P$ on mRNA expression of IL-1 $\beta$, IL- 6 , and TNF- $\alpha$ was confirmed by RT-PCR $(\mathbf{G})$ The results were determined using ImageJ software and expressed in arbitrary unit (A.U). Bars indicate mean expression in A.U \pm SEM. ** $p<0.01,{ }^{* * *} p<0.001$ compared to 5xFAD-mice and ${ }^{\# \# \#} p<0.001$ compared to WT-mice $(n=4)$.

2.3.4. Effect of Cyclopentanone Derivative 3NCP on Cytokines (IL-1 $\beta$, IL-6, TNF- $\alpha$ ) Protein Expression in FC and HC Tissues

The western blotting results reveal that the $3 \mathrm{NCP}$ at dose of $40 \mathrm{mg} / \mathrm{kg}$ cause a significant down regulation ofIL-1 $\beta$, IL-6, and TNF- $\alpha$ proteins expression in FC and HC of $5 x F A D$ mice as compared to the vehicle treated 5xFAD mice $(p<0.01, p<0.001)$ (Figure 8 ).
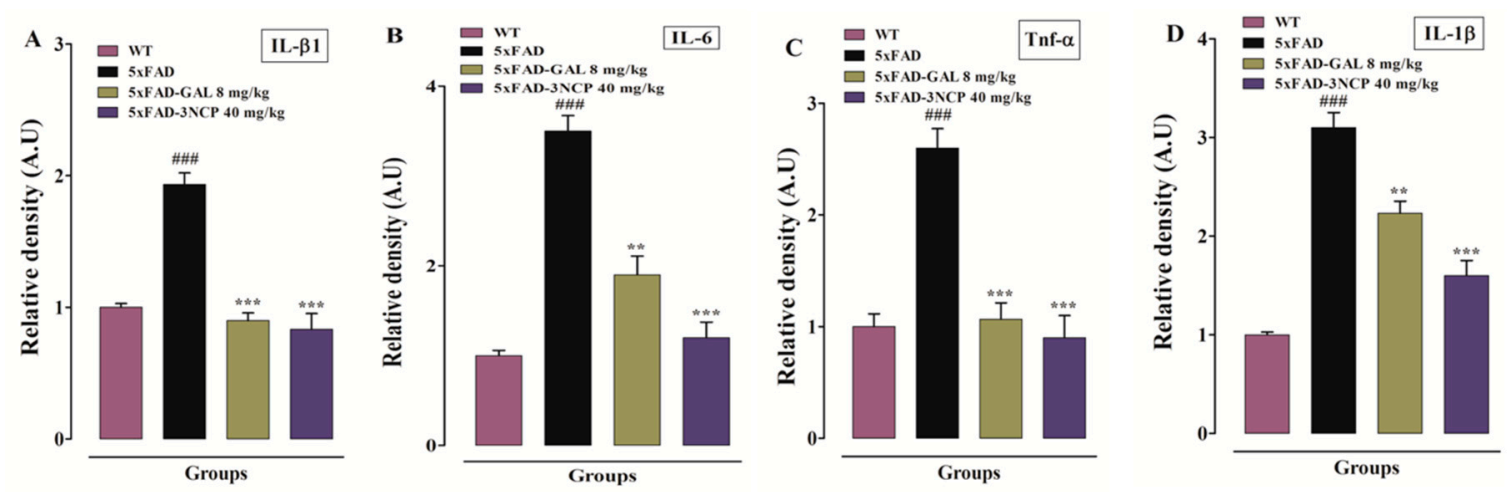

Figure 8. Cont. 

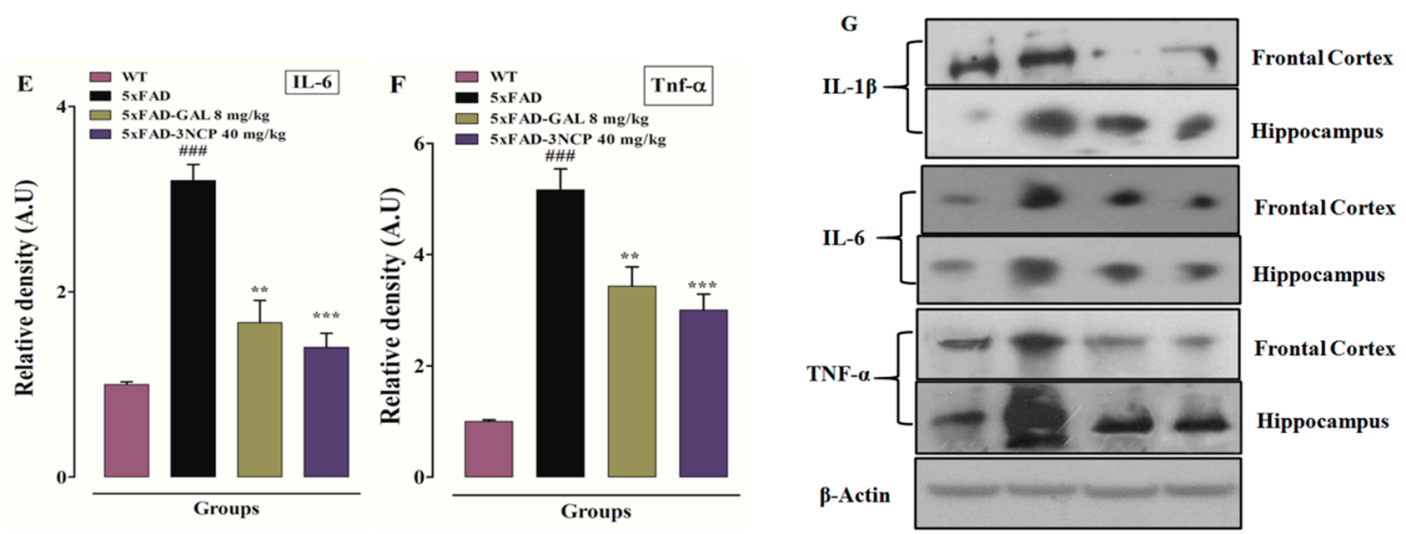

Figure 8. The relative density of IL- $\beta 1$ (A), IL-6 (B), TNF- $\alpha(\mathbf{C})$ in FC and relative density of IL- $\beta 1$ (D), IL-6 (E), and TNF- $\alpha(\mathbf{F})$ in HC of 5xFAD mice following treatment with 3NCP. Immunoblot of IL- $\beta 1$, IL-6, and TNF- $\alpha(G)$. $\beta$-Actin was used as the loading control. The results were determined using ImageJ software and expressed in arbitrary unit (A.U). Bars indicate mean in A.U \pm SEM. ${ }^{* *} p<0.01$, *** $p<0.001$ compared to 5xFAD-mice and ${ }^{\# \# \# ~} p<0.001$ compared to WT-mice $(n=4)$.

\section{Discussion}

Neuro-inflammation and oxidative stress have been described as possible pathophysiological mechanisms underlying AD. In addition, the cholinergic hypothesis contends that in AD patients, memory impairment is also linked with the deficit of cholinergic function in the brain. Although a number of drugs have been approved for the treatment of $\mathrm{AD}$, a majority of these drugs have a number of undesirable side effects and yield relatively diffident benefits [19].

Acetylcholine $(A C h)$ is the most crucial neurotransmitter involved in the regulation of cognitive functions. AChE inhibitors promote the endogenous levels of $A C h$ in the brain and thus enhance cholinergic transmission, whereas $B C h E$ inhibitors are believed to diminish neuritic plaques in the brain $[20,21]$. In this study, the anti-cholinesterase activities of $3 \mathrm{NCP}$ were assayed both in vitro and ex vivo. The in vitro anti-cholinesterases investigation revealed that the $3 \mathrm{NCP}$ has concentration-dependent $A C h E$ and $B C h E$ inhibition potential. The $3 \mathrm{NCP}$ exhibited $84.9 \%$ and $86.5 \%$ inhibition of $A C h E$ and $B C h E$ at concentration of $1000 \mu \mathrm{g} / \mathrm{mL}$, with $\mathrm{IC}_{50}$ values of 16.17 and $20.51 \mu \mathrm{g} / \mathrm{mL}$ against $A C h E$ and $B C h E$ (Table 1). The $3 \mathrm{NCP}$ inhibits the $A C h E$ and $B C h E$ activities in the HC and FC of the 5xFAD mice brain (Figure 2). Therefore, due to the inhibition of these enzymes, the acetylcholine levels are maintained in the synaptic cleft for a long time period, which causes stimulation of cholinergic receptors. This hike of cholinergic conduction may be the possible way in the restoration of memory in AD.

Due to its high oxygen consumption, the central nervous system is highly vulnerable to free radical and oxidative damage that play a pivotal role in the AD pathophysiology [22]. This leads to the generation of reactive oxygen species (ROS) such as superoxide anion radical, hydrogen peroxide, hydroxyl radical, and peroxyl radicals consequently resulting in oxidative stress [23,24].

Oxidative stress is known to play an important role in the pathogenesis of AD. The increased levels of $A \beta 1-40$ and $A \beta 1-42$ are due to more generation of oxidative products in the cortical and hippocampal tissues of AD patients [25]. Molecules with active antioxidant potential are used to scavenge such harmful radicals [19]. Glutathione, glutathione-S-transferase, and catalase are antioxidants that play a crucial role in the prevention or mitigation of free radicals mediated oxidative stress progression. Activities of these antioxidants decreases in AD individuals [26]. To remove peroxides, glutathione (GSH) works in conjunction with glutathione peroxidase (GPx) and produces oxidized glutathione (GSSG), which is reconverted to GSH by glutathione reductase (GR) with consumption of NADPH. A reduction in GSH may diminish clearance of hydrogen peroxide $\left(\mathrm{H}_{2} \mathrm{O}_{2}\right)$ and promote formation of $\mathrm{OH}$, hence increasing the free radical load, which triggers oxidative stress [1,2]. GST and catalase are antioxidant enzymes; being first line defense against oxidative injury [3]. The $3 \mathrm{NCP}$ has promising 
antioxidant potential, since it significantly improved activities of GST and catalase, and enhanced the level of GSH in HC and FC of transgenic 5xFAD mice.

Neuroinflammatory processes are fundamental characteristics of AD in which microglia are over activated, leading to increased production of pro-inflammatory cytokines. Moreover, deficiencies in the anti-inflammatory system may also contribute to neuro-inflammation [27]. It has been reported that inordinate production of inflammatory mediators and cytokines from activated microglia leads to unrestrained inflammation in neurodegenerative diseases [28-30]. Pro-inflammatory cytokines IL-1 $\beta$, TNF- $\alpha$, and IL- 6 are upregulated in 5xFAD transgenic mice and AD patients [31]. TNF- $\alpha$ level increases in hippocampal dependent cognitive impairment in rodents [32]. Halting generation of cytokines and pro-inflammatory mediators has become a therapeutic target in managing neurodegenerative diseases, and thus their down-regulation might aid in stopping or retarding the onset of AD [33]. The RT-PCR and western blotting studies reveal that the $3 \mathrm{NCP}$ significantly reduced the mRNA expression and protein level of these cytokines in the hippocampus and frontal cortex of 5xFAD transgenic mice. The results from RT-PCR and western blotting envisage the redemption of brain cells from these pro-inflammatory mediators by $3 \mathrm{NCP}$, advocate a role of the cyclopentanone derivatives as potential anti-inflammatory agents, and hence their role in the treatment of AD [34].

Open field (OF), rotarod, MWM, and Y-maze tests were conducted for determining the effect of $3 \mathrm{NCP}$ on the behavior of the test animals in terms of locomotion, motor coordination, hippocampal-dependent spatial learning and memory, and spatial recognition memory, respectively [35-37].

The OF assay has been an effective tool in measuring the anxiety-like behavior as reported in literature [38,39], and it has been extensively employed in the evaluation of the anxiolytic potential of many drugs, such as benzodiazepines (BDZs) [40-42]. A number of variables can be recorded from the OF test for the evaluation of anxiety (less distance travelling, less time spent in center and more time spent in periphery; indicate higher anxiety levels), risk assessment (sniffing, stretched attended posture; indicate inquisitive behaviour), locomotion (total distance travelled or total entries; indicate well-being) [43].

In this test, the 5xFAD mice spent same amount of time in the center as that of WT mice, showing a non-anxious behavior, showing a lack of anxiogenic effect due to $3 \mathrm{NCP}$. The more time spent in the center indicates a higher degree of anxiolysis and vice versa [44].

Assessing the motor coordination and balance can be taken advantage of not only to appraise the effects of test compounds or other experimental procedures on rodents, but also to portray the motor phenotype of transgenic/knockout animals [45].

For the assessment of motor coordination, mice were tested on a rotarod at a pre-set speed ( 0 to $40 \mathrm{rpm}$ ) for $5 \mathrm{~min}$ [37]. The results showed no significant difference in latency times of falling among $3 \mathrm{NCP}$ treated and the control animals implying that the prior one did not cause any motor deficits.

The water maze test has been most widely used to explore specific facets of spatial memory. This test is based upon the assumption that animals have acquired an optimal approach to delve into their environment and escape from the water with minimum efforts (swim the shortest possible distance) [46].

In MWM assay, during training trials, spatial-information acquisition was determined and in probe trails memory retention was assessed. Results of the study suggest that 5xFAD transgenic mice exhibited cognitive decline and required more time to find the escape platform in training trials as compared to WT mice. While in probe trial, 5xFAD mice displayed a significant decrease in time spent on target quadrant and number of target quadrant crossing. The $3 \mathrm{NCP}$ treatment significantly decreased latency time in training trials. In the Probe trial, 3NCP treated mice spent more time in the target quadrant and also crossed the platform position more frequently than transgenic mice treated with vehicle.

The MWM has proven to be a robust and reliable test that is strongly correlated with hippocampal synaptic plasticity and NMDA receptor function [47]. 
Spatial recognition and short term memory in mice can be assessed using Y-maze apparatus and this task is mediated via prefrontal cortex and hippocampal controls, respectively $[48,49]$. In the Y-maze test, reduced SAB (\%) was observed in the 5xFAD mice, which indicates impaired spatial memory. The $3 \mathrm{NCP}$ treatment improved the percent spontaneous alternation, reducing spatial memory impairment. This improvement in memory demonstrates the neuroprotective potential of $3 \mathrm{NCP}$ against memory impairment in the 5xFAD mice.

\section{Materials and Methods}

\subsection{Materials}

The 2-(hydroxyl-(3-nitrophenyl)methyl)cyclopentanone was gifted by Dr. Muhammad Naveed Umar (Department of Chemistry, University of Malakand, Chakdara, Pakistan). Acetylcholinesterase, butyrylcholinesterase, acetylthiocholine iodide, butyrylthiocholine iodide, 5,5-dithiobis(2-nitro-benzoic)acid, galantaminehydrobromide,1,1-diphenyl-2-picrylhydrazyl, hydrogen peroxide, trichloroacetic acid, sodium citrate, glutathione-S-transferase, 1-chloro-2,4-dinitrobenzene, dipotassium hydrogen phosphate, potassium dihydrogen phosphate, potassium hydroxide, ethylenediaminetetraacetic acid, boric acid, agarose, and ethidium bromide were obtained from Sigma-Aldrich (St. Louis, MO, USA). DNA extraction kit (Novel Genomic DNA Mini Kit), TRI-reagent (Bioshop, Burlington, ON, Canada), Tris (Scharlu, Barcelona, Spain), cDNA synthesis kit (ABM, Milton, ON, Canada), PCR primers (Macrogen, Seoul, Korea), PCR Master Mix, Taq polymerase (Thermo Fisher Scientific, Waltham, MA, USA), DNA Ladder, dNTPs, magnesium chloride (Invitrogen, Carlsbad, CA, USA) were purchased from local suppliers.

\subsection{Animals}

The $5 \times$ FAD mouse is a notable rodent model frequently used in the preclinical AD research. These mice present the common AD pathologies at an early age, beginning at 5 to 6 months of age [50]. They also resemble the human AD pathology in several ways, including, but not limited to, brain pathology, behavior, and biomarkers.

5xFAD mice were obtained from the Jackson Lab (Bar Harbor, ME, USA) and were housed under standard laboratory conditions in the animal house at the Department of Pharmacy, University of Peshawar, Pakistan. 5xFAD mice of either sex (age: 5-6 months) were used as a disease group and wild type mice littermates were used as control group. Experiments on animals and related procedures were approved by departmental ethical committee vide a reference number 12/EC-17/Pharm and were performed in agreement to the rules and regulations of Animals' Scientific Procedures Act (UK), 1986.

\subsection{In Vivo Activities}

\subsubsection{Genotyping of Transgenic Mice}

The genotyping methodology specified by Jackson Lab for strain transgenic mice was followed with minor modifications. Extraction of DNA was carried out using DNA extraction kit according to the manufacturer's protocol. PCR studies were performed following proper cyclic conditions. Two sets of primers were used in genotyping; sequences of these primers are shown in the Table 2 . PCR products were quantified through gel electrophoresis and amplified products were visualized using UV transilluminator [51]. 
Table 2. Primers sequences for PCR reaction.

\begin{tabular}{ll}
\hline \multicolumn{1}{c}{ Primer } & Sequence $\left(\mathbf{5}^{\prime} \mathbf{- 3}^{\prime} \mathbf{)}\right.$ \\
\hline Internal positive control & CTAGGCCACAGAATTGAAAGATCT \\
\hline Transgene & GTAGGTGGAAATTCTAGCATCATCC \\
\hline & AGGACTGACCACTCGACCAG \\
\hline IL-1 $\beta$ & CGGGGGTCTAGTTCTGCAT \\
\hline IL-6 & AGAAGCTTCCACCAATACTC \\
\hline & AGCACCTAGTTGTAAGGAAG \\
\hline TNF- $\alpha$ & GCCCTTCAGGAACAGCTATGA \\
\hline & TGTCAACAACATCAGTCCCAAGA \\
\hline GAPDH & CTTCTCCTTCCTGATCGTGG \\
\hline & GCTGGTTATCTCTCAGCTCCA \\
\hline
\end{tabular}

\subsubsection{Behavioral Activities}

Animal Grouping and Route of Drug Administration

Experimental mice were divided into six groups $(n=10$ each).

Group I: WT mice

Group II: 5xFAD mice

Group III: 5xFAD-GLN (8 mg/kg, i.p)

Group IV: 5xFAD-3NCP (10 mg/kg i.p)

Group V: 5xFAD-3NCP $(20 \mathrm{mg} / \mathrm{kg}$ i.p)

Group VI: 5xFAD-3NCP (40 mg/kg i.p)

Galantamine and 3NCP were dissolved in vehicle containing normal saline, Tween-80, and DMSO in a ratio of 93:2:5. Animals were treated with vehicle/galantamine/3NCP for 28 days.

\section{Open Field Test}

The open field test was performed for assessment of exploratory and locomotor activities of 5xFAD mice. Animals were placed in the center of arena and allowed for $5 \mathrm{~min}$ to explore. The number of rearing, grooming, and square crossing, the time spent in the center were recorded [52].

\section{Rotarod Test}

Rotarod tests were carried out for the assessment of motor coordination deficits, following the standard method with slight modifications [53]. All mice were trained for two days, four trials each day. It was performed for $5 \mathrm{~min}$ by placing each animal on the accelerating rod (4-40 rpm). On the next day after training trails, testing trials were carried out and after one hour of drug administration, the falling latency time was noted.

Morris Water Maze

The effect of 3NCP on the spatial learning and memory of 5xFAD mice was assessed through the Morris Water Maze apparatus (MWM, diameter: $110 \mathrm{~cm}$, height: $40 \mathrm{~cm}$ ) containing opaque water (depth: $20 \mathrm{~cm}$ ) maintained at $22-23^{\circ} \mathrm{C}$ ) according to reported method with minor modification [3]. The maze consisted of four quadrants with a submerged platform (diameter: $7 \mathrm{~cm}$ ) set $1 \mathrm{~cm}$ below the water-surface in one of these four quadrants. All mice were trained for five days continuously 
( 4 trials/day). The escape latency time to find the hidden platform was calculated. Those mice which failed to find the hidden platform in $60 \mathrm{~s}$, were manually guided, and allowed to stay for $10 \mathrm{~s}$ on the platform. At the 24th $\mathrm{h}$ after day 5 , the mice were assessed in probe trial for memory retention. The probe test was conducted without platform for $60 \mathrm{~s}$. The time spent by mice in target quadrant and the number of platform place crossings were measured. All activities were video recorded using an overhead camera.

\section{Y Maze Test}

The Y-maze test is utilized for the assessment of short term memory. Briefly, the mice were placed randomly at the center of the Y-maze and allowed for $8 \mathrm{~min}$ to move freely. The sequence of arm-entries was observed visually [54]. Spontaneous alternation behavior in percent was calculated through the following formula:

$$
\text { Spontaneous Alternation behavior }(\%)=\frac{\text { Number of overlaping entry sequences }}{\text { Total arm entries }-2} \times 100
$$

\subsection{In Vitro Assays}

Acetylcholinesterase and Butyrylcholinesterase Inhibition Assays

Acetylcholinesterase and butyrylcholinesterase assays were performed following Ellman's assay method [51]. Acetylthiocholine iodide (ATchI) and butyrylthiocholine iodide (BTchI) were used as substrates; degradation of these substrates leads to the formation of 5-thio-2-nitrobenzoate, which reacts with 5,5'-dithiobis (2-nitro-benzoate) (DTNB) and forms a yellow color complex, which was assayed at a wavelength of $412 \mathrm{~nm}$ through microplate reader.

The rate of absorbance $(\mathrm{V}=\Delta A B / \Delta t)$ showed the (\%) enzyme activity and inhibition by test/control samples and was calculated as follows:

$$
\begin{gathered}
\text { Enzyme inhibition (\%) }=100-\text { enzyme activity (\%) } \\
\text { Enzyme activity }(\%)=100 \times \mathrm{V} / \mathrm{V}_{\max }
\end{gathered}
$$

where $V_{\max }$ shows the maximum enzyme activity in the absence of the inhibitory agent.

\subsection{Ex Vivo Assays}

\subsubsection{Assessment of Inhibition of Cholinesterases ( $A C h E$ and BChE) in FC and HC}

This test was performed as described elsewhere [51,55]. After behavioral experiments, all mice were killed by decapitation under ether anesthesia; HC and FC were dissected and homogenized in ice-cold 0.1 M PBS buffer ( $\mathrm{pH}$ 8.0), the supernatant was separated and used in this assay. After ACh and $B C h$ degradation, thiocholine and acetate-thiocholine were formed, which was combined with DNTB that produced a yellow color complex, absorbance of that complex was measured at $412 \mathrm{~nm}$ in the 96-well microplate reader.

\subsubsection{Glutathione (GSH), Glutathione S-Transferase (GST), and Catalase Assay}

The level/activities of GSH, GST, and catalase in the hippocampus were determined as reported earlier in literature $[25,56]$. The supernatant of hippocampal homogenate was used in this test, which was obtained by homogenization and centrifugation of hippocampal tissue at speed of $1000 \times g$ at $4{ }^{\circ} \mathrm{C}$ for $15 \mathrm{~min}$. The GSH level, the GST, and catalase activities were measured by observing the absorbance variation through microplate reader at specific wavelengths (420, 240, and $340 \mathrm{~nm}$ ). 


\subsubsection{RT-PCR}

In RT-PCR, extraction of total RNA from the hippocampus and frontal cortex using TRI-reagent was carried out following the manufacturer's protocol. The purity of RNA was evaluated through a UV spectrophotometer. The cDNA was synthesized from total RNA via a cDNA synthesis kit. The targeted gene (IL-1 $\beta$, IL-6, TNF- $\alpha$ ) expressions were determined (Table 2). The housekeeping gene GAPDH was used as internal control. Through agarose gel (1.5\%) amplified products were separated and visualized using a UV transilluminator. The annealing temperature was $55^{\circ} \mathrm{C}$ of GAPDH and IL- $1 \beta, 60^{\circ} \mathrm{C}$ of IL- 6 and $62^{\circ} \mathrm{C}$ of TNF- $\alpha$. The expression of these cytokines was calculated in the arbitrary units (A.U.s) [57].

\subsubsection{Western Blot Analysis}

The western blot analysis was performed as reported previously [58]. Briefly, brain homogenates were quantified using Bio-Rad protein assay solution. The homogenates (30 $\mu \mathrm{g}$ protein) were fractionated using SDS-PAGE on a 15\% Bio-Rad Tetra cell (BioRad, Hercules, CA, USA). After transfer, the membranes were blocked in $5 \%$ skim milk (or BSA), incubated overnight at $4{ }^{\circ} \mathrm{C}$ with primary antibodies, and cross reacting proteins were detected using ECL after reaction with horseradish peroxidase-conjugated secondary antibodies. The primary antibodies, including mouse-derived anti-IL $6(24 \mathrm{kDa})$, anti-TNF- $\alpha$ (17.3 kDa), anti-p-IL-1 $\beta$ (17.5 kDA), and mouse-derived anti- $\beta$-actin (42 kDa) were purchased from Santa Cruz Biotechnology (Santa Cruz, CA, USA). After using membrane-derived secondary antibodies, ECL detection reagent (Bio-Rad) was used for visualization according to the manufacturer's instructions. The densitometry analysis of the bands was performed using ImageJ software (ImageJ-win64 1.8). The density values were calculated in arbitrary units (A.U.s) relative to the untreated control.

\subsection{Statistical Analysis}

The in vitro, SWM and Y-maze tests data were analyzed through two-way ANOVA followed by Bonferroni test, while ex vivo assays and SAB tests data were analyzed by one-way ANOVA followed by Tukey's post hoc test. Data of RT-PCR, Open field, and Rotarod tests were analyzed via one-way ANOVA followed by Dunnett posthoc test. Analyses were performed through GraphPad Prism 5 (GraphPad Prism Software Inc., San Diego, CA, USA) and statistical significance was set at $p<0.05$.

\section{Conclusions}

In conclusion, the results from this study indicate beneficial effects of 3NCP in the 5xFAD mice model. Moreover, improvements in cognitive performance with integral changes in behavioral performance, cholinesterases, oxidative stress, and inflammation were found to have a prospective association in the melioration of these parameters in 5xFAD mice. Further exploration of the relationship between inflammatory cytokine polymorphisms and AD risk may add to our understanding of $\mathrm{AD}$ pathogenesis and conduce to improved treatment strategies.

Author Contributions: Conceptualization, R.U. and G.A.; methodology, R.U. and G.A.; formal analysis, N.A., M.A., and M.U.A.; Resources, M.A., G.K. and M.N.U.; Writing-Original Draft Preparation, R.U.; writing-review and editing, R.U., N.A., and M.A.; Supervision, G.A.; Project administration, G.A. All authors have read and agreed to the published version of the manuscript.

Funding: This research was funded by Higher Education of Pakistan, under the National Research Programme for Universities (NRPU), grant no No.6671/KP/NRPU/R\&D/HEC/2016.

Acknowledgments: We are grateful to Muhammad SaeedJan, Department of Pharmacy, University of Malakand, and Shahid Ali Shah, Assistant Professor at Department of Biochemistry, Sarhad University of Science and technology, Peshawar for helping us in anti-Cholinesterases, and Western blotting activities.

Conflicts of Interest: The authors declare no conflict of interest. 


\section{References}

1. Maczurek, A.; Hager, K.; Kenklies, M.; Sharman, M.; Martins, R.; Engel, J.; Carlson, D.A.; Münch, G. Lipoic acid as an anti-inflammatory and neuroprotective treatment for Alzheimer's disease. Adv. Drug Deliv. Rev. 2008, 60, 1463-1470. [CrossRef] [PubMed]

2. Pfeffer, A.; Munder, T.; Schreyer, S.; Klein, C.; Rasińska, J.; Winter, Y.; Steiner, B. Behavioral and psychological symptoms of dementia (BPSD) and impaired cognition reflect unsuccessful neuronal compensation in the pre-plaque stage and serve as early markers for Alzheimer's disease in the APP23 mouse model. Behav. Brain Res. 2018, 347, 300-313. [CrossRef]

3. Zheng, H.; Zhou, Q.; Du, Y.; Li, C.; Xu, P.; Lin, L.; Xiao, J.; Gao, H. The hypothalamus as the primary brain region of metabolic abnormalities in APP/PS1 transgenic mouse model of Alzheimer's disease. BBA Mol. Basis Dis. 2018, 1864, 263-273. [CrossRef]

4. Shal, B.; Ding, W.; Ali, H.; Kim, Y.S.; Khan, S. Anti-neuroinflammatory Potential of Natural Products in Attenuation of Alzheimer's Disease. Front. Pharmacol. 2018, 9, 548. [CrossRef] [PubMed]

5. Imran, M.; Ullah, F.; Ayaz, M.; Sadiq, A.; Shah, M.R.; Jan, M.S.; Ullah, F. Anticholinesterase and antioxidant potentials of NoneamicranthaBioss. \&Reut along with GC-MS analysis. BMC Complement. Altern. Med. 2017, 17, 499 .

6. Öztürk, M.; Kolak, U.; Topçu, G.; Öksüz, S.; Choudhary, M.I. Antioxidant and anticholinesterase active constituents from Micromeriacilicica by radical-scavenging activity-guided fractionation. Food Chem. 2011, 126, 31-38. [CrossRef]

7. Stuchbury, G.; Münch, G. Alzheimer's associated inflammation, potential drug targets and future therapies. J. Neural. Transm. 2005, 112, 429-453. [CrossRef]

8. Martono, S. Benzylidene cyclopentanone derivatives as inhibitors of rat liver glutathione s-transferase activities. Indones. J. Chem. 2010, 5, 71-75. [CrossRef]

9. Hoan, D.Q.; Chi, N.Q.; Hien, N. Preparing and evaluating the antioxidant of an acid derivative from a monocarbonylcurcumin analog of cyclopentanone. TapchiKhoahoc 2016, 12, 60-65.

10. KunhannaSarojini, B.; GovindarajuDarshan Raj, C.; Kyathegowda Ramakrishna, M.; Ramesh, S.R.; RudreshBharath, B.; Manjunatha, H. In Silico Studies of (2E, 5E)-2, 5-bis (3-methoxy-4-hydroxy-benzylidene) Cyclopentanone on Proteins AChE and BChE Involved in Alzheimers disease and Ameliorative Effects on Paraquat Induced Oxidative Stress Markers in Drosophila melanogaster. Lett. Drug Des. Discov. 2011, 8, 260-267. [CrossRef]

11. Ahmed, T.; Khan, A.-U.; Abbass, M.; Rodrigues Filho, E.; Din, Z.U.; Khan, A. Synthesis, characterization, molecular docking, analgesic, antiplatelet and anticoagulant effects of dibenzylidene ketone derivatives. Chem. Cent. J. 2018, 12, 134. [CrossRef] [PubMed]

12. Tian, H.; Gao, J.-l.; Xu, H.; Zheng, L.-Y.; Huang, W.-B.; Liu, Q.-W.; Zhang, S.-Q. Proline-based dipeptides as efficient organocatalysts for asymmetric aldol reactions in brine. Tetrahedron Asymmetry 2011, 22, 1074-1080. [CrossRef]

13. Secci, D.; Carradori, S.; Petzer, A.; Guglielmi, P.; D’Ascenzio, M.; Chimenti, P.; Bagetta, D.; Alcaro, S.; Zengin, G.; Petzer, J.P. 4-(3-Nitrophenyl) thiazol-2-ylhydrazone derivatives as antioxidants and selective hMAO-B inhibitors: Synthesis, biological activity and computational analysis. J. Enzyme Inhib. Med. Chem. 2019, 34, 597-612. [CrossRef] [PubMed]

14. Benabdesselam, S.; Izza, H.; Lanez, T.; Guechi, E. Synthesis, antioxidant and antibacterial activities of 3-nitrophenyl ferrocene. In Proceedings of the IOP Conference Series: Materials Science and Engineering, Dubai, UAE, 24-26 November 2017; p. 012007.

15. Shruthi, C.D.; Shetty, V.R.; Suresh, G.S. Indian Journal of Advances in Chemical Science. Indian J. Adv. Chem. Sci. 2018, 6, 182-186.

16. Brinkerhoff, R.C.; Santa-Helena, E.; do Amaral, P.C.; Cabrera, D.D.C.; Ongaratto, R.F.; de Oliveira, P.M.; D'Oca, C.D.R.M.; Gonçalves, C.A.N.; Nery, L.E.M.; D'Oca, M.G.M. Evaluation of the antioxidant activities of fatty polyhydroquinolines synthesized by Hantzsch multicomponent reactions. RSC Adv. 2019, 9, 24688-24698. [CrossRef]

17. De Resende, M.F.; Lino, C.I.; de Souza-Fagundes, E.M.; Rettore, J.V.P.; de Oliveira, R.B.; Labanca, R.A. Assessment of anti-diabetic activity of a novel hydrazine-thiazole derivative: In vitro and in vivo method. Braz. J. Pharm. Sci. 2019, 55. [CrossRef] 
18. Henderson, S.T. Ketone bodies as a therapeutic for Alzheimer's disease. Neurotherapeutics 2008, 5, 470-480. [CrossRef]

19. Gany, S.A.; Tan, S.C.; Gan, S.Y. Antioxidative, anticholinesterase and anti-neuroinflammatory properties of Malaysian brown and green seaweeds. IJIME 2015, 8, 1269-1275.

20. Das, A.; Shanker, G.; Nath, C.; Pal, R.; Singh, S.; Singh, H.K. A comparative study in rodents of standardized extracts of Bacopamonniera and Ginkgo biloba: Anticholinesterase and cognitive enhancing activities. Pharmacol. Biochem. Behav. 2002, 73, 893-900. [CrossRef]

21. Deng, G.; Wu, C.; Rong, X.; Li, S.; Ju, Z.; Wang, Y.; Ma, C.; Ding, W.; Guan, H.; Cheng, X. Ameliorative effect of deoxyvasicine on scopolamine-induced cognitive dysfunction by restoration of cholinergic function in mice. Phytomedicine 2019, 63, 153007. [CrossRef]

22. Li, J.; Li, W.; Jiang, Z.-G.; Ghanbari, H.A. Oxidative stress and neurodegenerative disorders. Int. J. Mol. Sci. 2013, 14, 24438-24475. [CrossRef] [PubMed]

23. Ghasemzadeh, A.; Jaafar, H.Z.; Rahmat, A. Antioxidant activities, total phenolics and flavonoids content in two varieties of Malaysia young ginger (Zingiber officinale Roscoe). Molecules 2010, 15, 4324-4333. [CrossRef] [PubMed]

24. Madamanchi, N.R.; Vendrov, A.; Runge, M.S. Oxidative stress and vascular disease. Arter. Thromb. Vasc. Biol. 2005, 25, 29-38. [CrossRef]

25. Cheignon, C.; Tomas, M.; Bonnefont-Rousselot, D.; Faller, P.; Hureau, C.; Collin, F. Oxidative stress and the amyloid beta peptide in Alzheimer's disease. Redox Biol. 2018, 14, 450-464. [CrossRef]

26. Mates, J. Effects of antioxidant enzymes in the molecular control of reactive oxygen species toxicology. Toxicology 2000, 153, 83-104. [CrossRef]

27. Su, F.; Bai, F.; Zhang, Z. Inflammatory Cytokines and Alzheimer's Disease: A Review from the Perspective of Genetic Polymorphisms. Neurosci. Bull. 2016, 32, 469-480. [CrossRef]

28. Jung, H.W.; Yoon, C.-H.; Park, K.M.; Han, H.S.; Park, Y.-K. Hexane fraction of ZingiberisRhizomaCrudus extract inhibits the production of nitric oxide and proinflammatory cytokines in LPS-stimulated BV2 microglial cells via the NF-kappaB pathway. Food Chem. Toxicol. 2009, 47, 1190-1197. [CrossRef]

29. Wong, A.; Lüth, H.J.; Deuther-Conrad, W.; Dukic-Stefanovic, S.; Gasic-Milenkovic, J.; Arendt, T.; Münch, G. Advanced glycationendproducts co-localize with inducible nitric oxide synthase in Alzheimer's disease. Brain Res. 2001, 920, 32-40. [CrossRef]

30. Griffin, W.S.T.; Sheng, J.G.; Roberts, G.W.; Mrak, R.E. Interleukin-1 expression in different plaque types in Alzheimer's disease: Significance in plaque evolution. J. Neuropathol. Exp. Neurol. 1995, 54, $276-281$. [CrossRef]

31. van Gijsel-Bonnello, M.; Baranger, K.; Benech, P.; Rivera, S.; Khrestchatisky, M.; de Reggi, M.; Gharib, B. Metabolic changes and inflammation in cultured astrocytes from the 5xFAD mouse model of Alzheimer's disease: Alleviation by pantethine. PLoS ONE 2017, 12, e0175369. [CrossRef]

32. Yang, H.; Xie, J.; Mu, W.; Ruan, X.; Zhang, J.; Yao, L.; Diao, Z.; Wu, M.; Li, Y.; Ren, W. Tea polyphenols protect learning and memory in sleep-deprived mice by promoting AMPA receptor internalization. Neuroreport 2020, 31, 857-864. [CrossRef] [PubMed]

33. Wang, W.-Y.; Tan, M.-S.; Yu, J.-T.; Tan, L. Role of pro-inflammatory cytokines released from microglia in Alzheimer's disease. Ann. Transl. Med. 2015, 3, 136. [PubMed]

34. Pan, M.-H.; Lin-Shiau, S.-Y.; Lin, J.-K. Comparative studies on the suppression of nitric oxide synthase by curcumin and its hydrogenated metabolites through down-regulation of IKB kinase and NFkB activation in macrophages. Biochem. Pharmacol. 2000, 60, 1665-1676. [CrossRef]

35. Wagner, J.M.; Sichler, M.E.; Schleicher, E.M.; Franke, T.N.; Irwin, C.; Löw, M.J.; Beindorff, N.; Bouter, C.; Bayer, T.A.; Bouter, Y. Analysis of motor function in the Tg4-42 mouse model of Alzheimer's disease. Front. Behav. Neurosci. 2019, 13, 107. [CrossRef]

36. Hui, J.; Feng, G.; Zheng, C.; Jin, H.; Jia, N. Maternal separation exacerbates Alzheimer's disease-like behavioral and pathological changes in adult APPswe/PS1dE9 mice. Behav. Brain Res. 2017, 318, 18-23. [CrossRef] 
37. Brooks, S.P.; Dunnett, S.B. Tests to assess motor phenotype in mice: A user's guide. Nat. Rev. Neurosci. 2009, 10, 519-529. [CrossRef]

38. Einat, H.; Yuan, P.; Manji, H.K. Increased anxiety-like behaviors and mitochondrial dysfunction in mice with targeted mutation of the Bcl-2 gene: Further support for the involvement of mitochondrial function in anxiety disorders. Behav. Brain Res. 2005, 165, 172-180. [CrossRef] [PubMed]

39. Sturman, O.; Germain, P.-L.; Bohacek, J. Exploratory rearing: A context-and stress-sensitive behavior recorded in the open-field test. Stress 2018, 21, 443-452. [CrossRef]

40. Beaufour, C.C.; Le Bihan, C.; Hamon, M.; Thiébot, M.-H. Extracellular dopamine in the rat prefrontal cortex during reward-, punishment-and novelty-associated behaviour. Effects of diazepam. Pharmacol. Biochem. Behav. 2001, 69, 133-142. [CrossRef]

41. Nitz, D.A. Tracking route progression in the posterior parietal cortex. Neuron 2006, 49, 747-756. [CrossRef]

42. Fan, J.; Li, D.; Chen, H.S.; Huang, J.G.; Xu, J.F.; Zhu, W.W.; Chen, J.G.; Wang, F. Metformin produces anxiolytic-like effects in rats by facilitating GABAA receptor trafficking to membrane. Br. J. Pharmacol. 2019, 176, 297-316. [CrossRef] [PubMed]

43. Sestakova, N.; Puzserova, A.; Kluknavsky, M.; Bernatova, I. Determination of motor activity and anxiety-related behaviour in rodents: Methodological aspects and role of nitric oxide. Interdiscip. Toxicol. 2013, 6, 126-135. [CrossRef]

44. Bartolomé, I.; Llidó, A.; Darbra, S.; Pallarès, M. Early postnatal neuroactive steroid manipulation differentially affects recognition memory and passive avoidance performance in male rats. Behav. Brain Res. 2020, 394, 112833.

45. Carter, R.J.; Morton, J.; Dunnett, S.B. Motor coordination and balance in rodents. Curr. Protoc. Neurosci. 2001, 15, 8.12.1-8.12.14. [CrossRef] [PubMed]

46. Wenk, G.L. Assessment of spatial memory using the radial arm maze and Morris water maze. Curr. Protoc. Neurosci. 2004, 26, 8.5A.1-8.5A.12. [CrossRef]

47. Vorhees, C.V.; Williams, M.T. Morris water maze: Procedures for assessing spatial and related forms of learning and memory. Nat. Protoc. 2006, 1, 848-858. [CrossRef]

48. Ali, T.; Kim, M.O. Melatonin ameliorates amyloid beta-induced memory deficits, tau hyperphosphorylation and neurodegeneration via PI 3/Akt/GS k3 $\beta$ pathway in the mouse hippocampus. J. Pineal. Res. 2015, 59, 47-59. [CrossRef]

49. Kraeuter, A.-K.; Guest, P.C.; Sarnyai, Z. The Y-Maze for assessment of spatial working and reference memory in mice. In Pre-Clinical Models; Springer: Berlin/Heidelberg, Germany, 2019; pp. 105-111.

50. Oakley, H.; Cole, S.L.; Logan, S.; Maus, E.; Shao, P.; Craft, J.; Guillozet-Bongaarts, A.; Ohno, M.; Disterhoft, J.; Van Eldik, L. Intraneuronal $\beta$-amyloid aggregates, neurodegeneration, and neuron loss in transgenic mice with five familial Alzheimer's disease mutations: Potential factors in amyloid plaque formation. J. Neurosci. 2006, 26, 10129-10140. [CrossRef]

51. Ellman, G.L.; Courtney, K.D.; Andres Jr, V.; Featherstone, R.M. A new and rapid colorimetric determination of acetylcholinesterase activity. Biochem. Pharmacol. 1961, 7, 88-95. [CrossRef]

52. Semmler, A.; Frisch, C.; Debeir, T.; Ramanathan, M.; Okulla, T.; Klockgether, T.; Heneka, M.T. Long-term cognitive impairment, neuronal loss and reduced cortical cholinergic innervation after recovery from sepsis in a rodent model. Exp. Neurol. 2007, 204, 733-740. [CrossRef]

53. Gao, J.; Wang, L.; Gao, C.; Arakawa, H.; Perry, G.; Wang, X. TDP-43 inhibitory peptide alleviates neurodegeneration and memory loss in an APP transgenic mouse model for Alzheimer's disease. BBA Mol. Basis Dis. 2020, 1866, 165580. [CrossRef] [PubMed]

54. Wu, X.; Kosaraju, J.; Zhou, W.; Tam, K.Y. SLOH, a carbazole-based fluorophore, mitigates neuropathology and behavioral impairment in the triple-transgenic mouse model of Alzheimer's disease. Neuropharmacology 2018, 131, 351-363. [CrossRef] [PubMed]

55. Bradford, M.M. A rapid and sensitive method for the quantitation of microgram quantities of protein utilizing the principle of protein-dye binding. Anal. Biochem. 1976, 72, 248-254. [CrossRef]

56. Naveed, M.; Khan, S.Z.; Zeeshan, S.; Khan, A.; Shal, B.; Atiq, A.; Ali, H.; Ullah, R.; Khan, S. A new cationic palladium (II) dithiocarbamate exhibits anti-inflammatory, analgesic, and antipyretic activities through inhibition of inflammatory mediators in in vivo models. Naunyn-Schmiedeberg's Arch. Pharmacol. 2019, 392, 961-977. [CrossRef] [PubMed] 
57. Khalid, S.; Ullah, M.Z.; Khan, A.U.; Afridi, R.; Rasheed, H.; Khan, A.; Ali, H.; Kim, Y.S.; Khan, S. Antihyperalgesic properties of honokiol in inflammatory pain models by targeting of NF- $\mathrm{B}$ and Nrf2 signaling. Front. Pharmacol. 2018, 9, 140. [CrossRef]

58. Shah, S.; Yoon, G.; Chung, S.; Abid, M.; Kim, T.; Lee, H.; Kim, M. Novel osmotin inhibits SREBP2 via the AdipoR1/AMPK/SIRT1 pathway to improve Alzheimer's disease neuropathological deficits. Mol. Psychiatry 2017, 22, 407-416. [CrossRef]

Publisher's Note: MDPI stays neutral with regard to jurisdictional claims in published maps and institutional affiliations.

(C) 2020 by the authors. Licensee MDPI, Basel, Switzerland. This article is an open access article distributed under the terms and conditions of the Creative Commons Attribution (CC BY) license (http://creativecommons.org/licenses/by/4.0/). 